\title{
Editorial
}

\section{El impacto de la era digital en el diagnóstico cefalómetrico}

Irene Gabriela Bruno ${ }^{1}$

\author{
1 Odontóloga, Prof. Tit. Diagnóstico por Imágenes, Escuela de \\ Odontología, Universidad del Salvador
}

Rev Argent Radiol 2021;85:31-32.

En el presente número contamos con la colaboración de Calle-Velezmoro y col, ${ }^{1}$ quienes han realizado un trabajo observacional, analítico, transversal, retrospectivo, comparando la diferencia del trazado cefalométrico digital con el trazado convencional en radiografías laterales de cráneo.

El análisis cefalométrico tiene algunas limitaciones, que tienen que ver con la adquisición de la imagen y la identificación de los puntos anatómicos. Los errores que se producen se pueden clasificar en errores de proyección (adquisición), errores de identificación de puntos cefalométricos y errores de medición. ${ }^{1-4}$ Los errores de proyección comprenden los errores por posicionamiento del paciente, magnificación o distorsión, diferente tamaño de estructuras bilaterales y superposición de estructuras craneofaciales - lo que complica la localización precisa de los puntos de referencia cefalométricos. ${ }^{5}$ También puede haber errores durante la digitalización de la imagen convencional.

La principal fuente de error en el análisis cefalométrico es la identificación del punto cefalométrico anatómico, que puede estar enmascarado, superpuesto o borroso. ${ }^{1,6}$ La localización de los puntos de referencia se complica aún más por una asimetría significativa, como en los pacientes con síndromes craneofaciales. A pesar de estos problemas, los cefalogramas se han utilizado para la planificación y el seguimiento quirúrgico craneofacial y ortognático, debido a la facilidad de reproducción y el bajo costo.

En cambio, cuando se marcan los puntos cefalómetricos correspondientes a las piezas dentarias - que en este trabajo y en otros se encuentran con diferencias significativas, como el ángulo interincisal -, el principal inconveniente es que los pacientes a los que se les indican estos estudios presentan, en su mayoría, apiñamiento dentario anterior. ${ }^{1}$ Por lo tanto, hay que determinar el eje longitudinal de la pieza dentaria, el operador debe seleccionar cuál es la pieza más representativa. Hay opiniones encontradas en este punto: algunos opinan que debería elegirse la pieza más anterior, porque es el más desfavorable, mientras otros prefieren hacer la media, porque consideran que es la más representativa. Muchos estudios se han realizado comparando los dos métodos en cuanto a confiabilidad, exactitud, reproductibilidad; la mayoría coincide en que no hay diferencias significativas entre ambos métodos. 7,8

Los criterios más importantes para utilizar un método manual o digital es que debe ser exacto, preciso y debe mostrar una alta tasa de reproducibilidad en los trazados y en el análisis. ${ }^{9}$ Sin embargo, es de preferencia la radiografía digital, ya que no necesita ser escaneada, por lo que es más rápida y no presenta el error de la conversión de la imagen. ${ }^{10}$ La identificación de puntos de referencia es tan importante como el tipo de estudio. Se ha encontrado que el error interoperador en general es mayor que el error intraoperador. ${ }^{11}$ Por lo tanto, la confiabilidad de la identificación de los puntos cefalométricos en determinadas zonas anatómicas es operador dependiente.

Por último, en la actualidad, hay una tendencia a realizar cefalometrías 3D, debido a que eliminan todos los inconvenientes de las imágenes bidimensionales y proporcionan una localización más exacta de los puntos cefalométricos.

\section{Bibliografía}

1 Calle-Velezmoro E, Calle-Morocho J, Morales-Vadillo R. GuevaraCanales. Comparación entre trazados cefalométricos manual y digital en radiografías laterales del cráneo. Rev Argent Radiol. 2021;85(02):33-40

2 Ferreira JT, Telles CdeS. Evaluation of the reliability of computerized profile cephalometric analysis. Braz Dent J. 2002;13(03): 201-204

3 Navarro Rde L, Oltramari-Navarro PV, Fernandes TM, Oliveira GF, Conti AC, Almeida MR. Comparison of manual, digital and lateral CBCT cephalometric analyses. J Appl Oral Sci. 2013;21(02): 167-176

4 Houston WJ. The analysis of errors in orthodontic measurements. Am J Orthod. 1983;83(05):382-390
Dirección para correspondencia Irene Gabriela Bruno, Odontóloga, Prof. Tit. Diagnóstico por Imágenes, Escuela de Odontología, Universidad del Salvador (e-mail: dragbruno@yahoo.com.ar).
DOI https://doi.org/ $10.1055 / \mathrm{s}-0041-1731642$. ISSN 1852-9992.
(C) 2021. Asociación Civil Sociedad Argentina de Radiología and Federacion Argentina de Asociaciones de Radiología, Diagnóstico por Imágenes y Terapia Radiante. All rights reserved.

This is an open access article published by Thieme under the terms of the Creative Commons Attribution-NonDerivative-NonCommercial-License, permitting copying and reproduction so long as the original work is given appropriate credit. Contents may not be used for commercial purposes, or adapted, remixed, transformed or built upon. (https://creativecommons.org/ licenses/by-nc-nd/4.0/)

Thieme Revinter Publicações Ltda., Rua do Matoso 170, Rio de Janeiro, RJ, CEP 20270-135, Brazil 
5 Goracci C, Ferrari M. Reproducibility of measurements in tabletassisted, PC-aided, and manual cephalometric analysis. Angle Orthod. 2014;84(03):437-442

6 AlBarakati S, Kula K, Ghoneima A. The reliability and reproducibility of cephalometric measurements: a comparison of conventional and digital methods. Dentomaxillo facial Radiol. 2012;41(01):11-17

7 Lalakiya H, Baswaraj, Agrawal C, Patel U, Ramani A, Patel V, et al. The comparison of computer aided digital cephalometric radiograph with manual tracing. Int J Adv Res (Indore). 2016;4(01):621-626

8 Sandler PJ. Reproducibility of cephalometric measurements. Br J Orthod. 1988;15(02):105-110
9 Prabhakar R, Rajakumar P, Karthikeyan MK, Saravanan R, Vikram NR, Reddy A. A hard tissue cephalometric comparative study between hand tracing and computerized tracing. J Pharm Bioallied Sci. 2014;6(01, Suppl 1):S101-S106

10 Sayinsu K, Isik F, Trakyali G, Arun T. An evaluation of the errors in cephalometric measurements on scanned cephalometric images and conventional tracings. Eur J Orthod. 2007;29(01):105-108

11 Jung PK, Lee GC, Moon CH. Comparison of cone-beam computed tomography cephalometric measurements using a midsagittal projection and conventional two-dimensional cephalometric measurements. Korean J Orthod. 2015;45(06):282-288 